Supplementary Information:

\title{
Copper/Silver Bimetallic Nanoparticles Supported on Aluminosilicate Geomaterials
} as Antibacterial Agents

Edgardo Cruces $^{a, b *}$, Nicolás Arancibia-Miranda ${ }^{b, c}$, Karen Manquián-Cerdac, François Perreault ${ }^{\mathrm{d}}$, Nanthi Bolane,f, Manuel Ignacio Azócarc, Victor Cubillos ${ }^{\mathrm{g}}$, Jaime Montory ${ }^{\mathrm{h}}$, María Angélica Rubiob,c, Binoy Sarkari*

a Centro de Investigaciones Costeras Universidad de Atacama (CIC-UDA), Avenida Copayapu 485, Copiapó, Chile

b Center for the Development of Nanoscience and Nanotechnology, CEDENNA, 9170124, Santiago, Chile

c Facultad de Química y Biología, Universidad de Santiago de Chile, Av. B. O’Higgins, 363, Santiago, Chile

d School of Sustainable Engineering and the Built Environment, Arizona State University, Tempe, $A Z$, USA

e School of Agriculture and Environment, The University of Western Australia, Perth, WA 6001, Australia

f The UWA Institute of Agriculture, The University of Western Australia, Perth, WA 6001, Australia g Instituto Ciencias Marinas y Limnológicas, Universidad Austral de Chile, Valdivia, Chile h Centro i mar, Universidad de Los Lagos, Casilla 557, Puerto Montt, Chile

' Lancaster Environment Centre, Lancaster University, Lancaster, LA1 4YQ, United Kingdom

*Corresponding authors: edgardo.cruces@usach.cl (E. Cruces)

b.sarkar@lancaster.ac.uk (B. Sarkar) 


\section{Supporting figures}
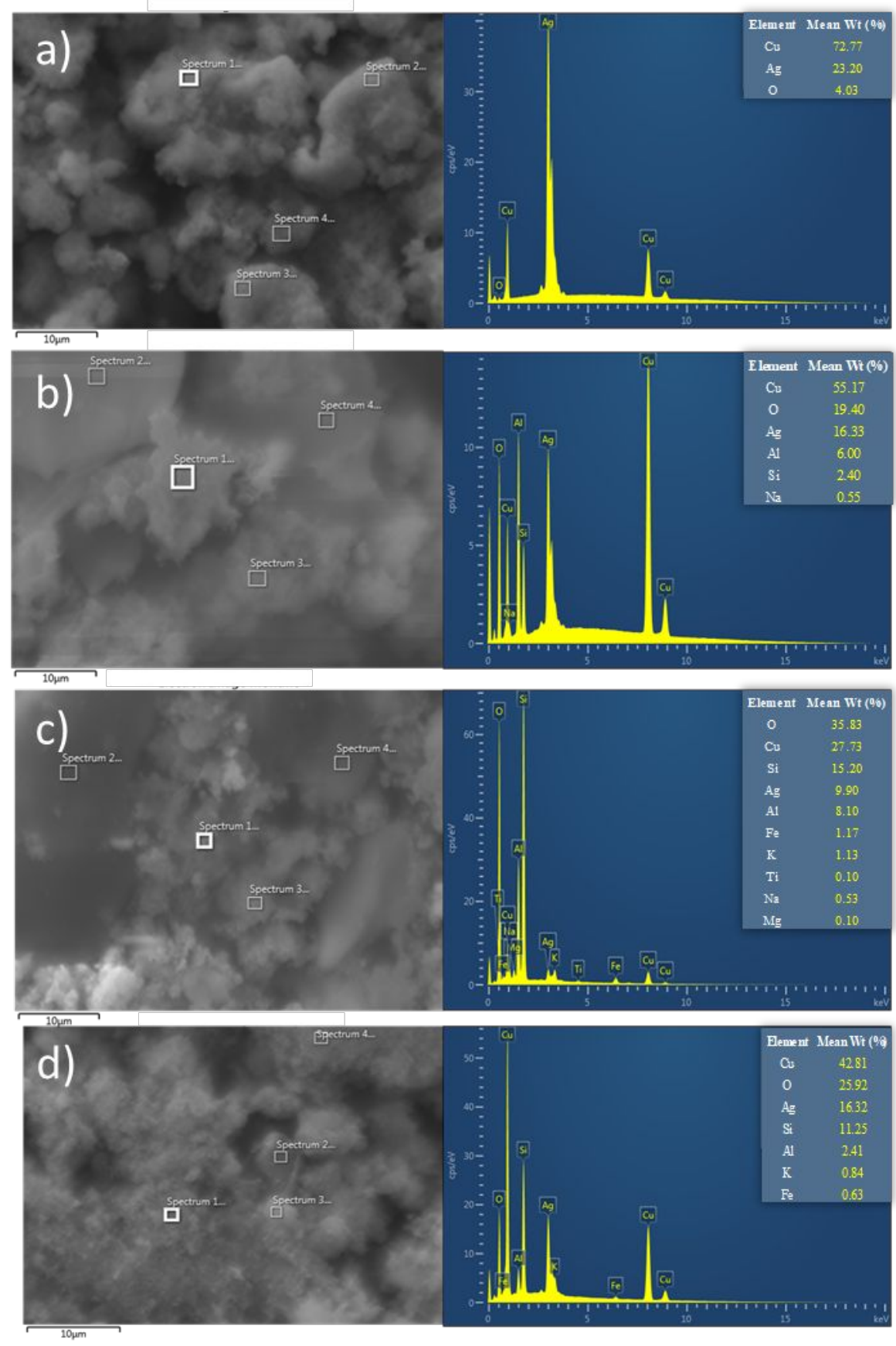

Figure S1. SEM images and EDS spectra of (a) Cu/Ag bimetallic NPs, (b) Imo_Cu/Ag, (c) Mtt_Cu/Ag and (d) Zeo_Cu/Ag. 

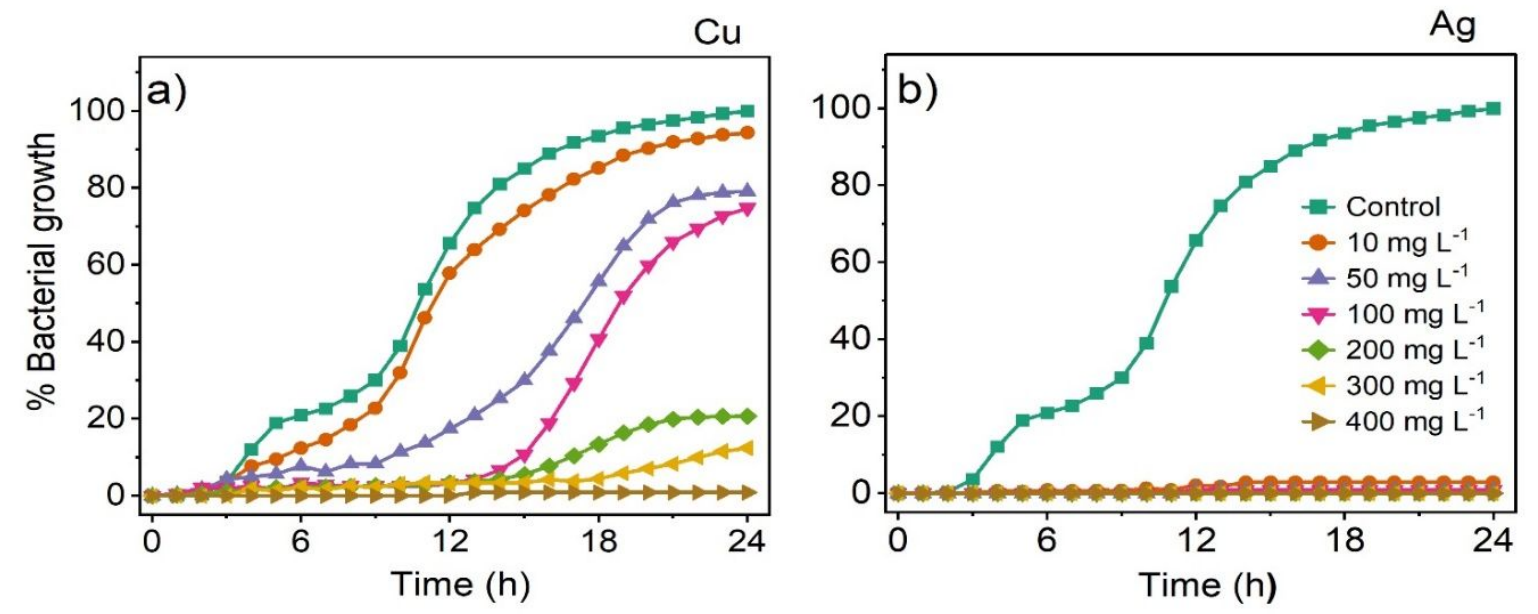

Figure S2. Effect of Cu (a) and Ag (b) NPs on the growth of Escherichia coli over $24 \mathrm{~h}$ at particle concentrations of $10,50,100,200,300$ and $400 \mathrm{mg} \cdot \mathrm{L}^{-1}$. For the preparation of $\mathrm{Cu}$ and $\mathrm{Ag} \mathrm{NPs}$, to $1.0 \mathrm{~mol} \cdot \mathrm{L}^{-1} \mathrm{CuCl}_{2} \cdot 6 \mathrm{H}_{2} \mathrm{O}$ or $\mathrm{AgNO}_{3}$ aqueous solution, $1.6 \mathrm{~mol} \cdot \mathrm{L}^{-1} \mathrm{NaBH}_{4}$ solution was added dropwise at room temperature under continuous mechanical stirring, according to Sepulveda et al (2018). The resulting solution was centrifuged at $9000 \mathrm{rpm}$ for $10 \mathrm{~min}$, and the supernatant was replaced with ethanol/water. To avoid oxidation of the NPs, an ethanol/water wash was performed, resulting in a fine powder product after lyophilization. 


\section{Supporting table}

Table S1. Minimum inhibitory concentration at $24 \mathrm{~h}$ (MIC) for $E$. coli in relation to different percentages of $\mathrm{Ag}$ and $\mathrm{Cu}$ used for the synthesis of bimetallic NPs. Bimetallic NPs concentrations of $50,75,100,150,200$ and $400 \mathrm{mg} \cdot \mathrm{L}^{-1}$ were used for the determination $(\mathrm{n}=3)$.

\begin{tabular}{lll}
\hline $\mathrm{Ag}$ & $\mathrm{Cu}$ & $\mathrm{MIC}$ \\
$\%$ & $\%$ & $\left(\mathrm{mg} \cdot \mathrm{L}^{-1}\right)$ \\
\hline 5 & 95 & 400 \\
10 & 90 & 200 \\
15 & 85 & 150 \\
20 & 80 & 100 \\
25 & 75 & 100 \\
30 & 70 & 75 \\
35 & 65 & 50 \\
40 & 60 & 50 \\
45 & 55 & 50 \\
50 & 50 & 50 \\
\hline
\end{tabular}

